\title{
Biotic and abiotic factors controlling the spatial and temporal variation of soil respiration in an agricultural ecosystem
}

\author{
Guangxuan Han, Guangsheng Zhou*, Zhenzhu Xu, Yang Yang, Jingli Liu, Kuiqiao Shi \\ Laboratory of Quantitative Vegetation Ecology, Institute of Botany, The Chinese Academy of Sciences, 20 Nanxincun, Xiangshan, \\ Haidian District, Beijing 100093, PR China
}

Received 13 May 2006; received in revised form 29 July 2006; accepted 11 August 2006

Available online 18 September 2006

\begin{abstract}
Based on the continuous observation of soil respiration and environmental factors in a maize ecosystem from late April to late September in 2005, the spatial and temporal variation of soil respiration and their controlling factors were analyzed. There was a significant spatial pattern for soil respiration at the plant scale and higher soil respiration rates tended to occur near the maize plant during the growing season. On one measurement moment, root biomass $(B)$ in soil collars exerted significant influence on the spatial pattern of soil respiration under the relatively homogeneous environmental conditions. A linear relationship existed between soil respiration rate and root biomass
\end{abstract}

$\mathrm{SR}=\alpha B+\beta$.

At daily scale, the coefficient $\alpha$ and $\beta$ in Eq. (1) fluctuated because soil temperature $(T)$ markedly reduced the intercept $(\beta)$ of the linear equation and significantly increased its slope $(\alpha)$. Based on this, we developed

$\mathrm{SR}=a e^{b T} B+c T+d$.

Eq. (2) indicated that increasing soil temperature ameliorated the positive relationship between soil respiration and root biomass in the daily variation of soil respiration. At seasonal scale, parameter $a, b$ and $c$ in Eq. (2) were affected mainly by soil moisture ( $W$ ), soil temperature and net primary productivity (NPP), respectively. Thus, we developed

$\mathrm{SR}=(a W+b) e^{c T} B+(d \mathrm{NPP}+e) T+f$

to estimate soil respiration during the growing season. Eq. (3) demonstrated that soil temperature, soil moisture, root biomass and NPP combined affected soil respiration at season scale, and they accounted for $78 \%$ of the seasonal and spatial variation of soil respiration during the growing season. Eq. (3) not only took into account the influence of soil temperature and moisture, but also incorporated biotic factors as predictor variables, which would lead to an improvement in predictive capabilities of the model. Moreover, Eq. (3) could simulate instantaneous soil respiration rates from different sampling points and at different temporal scales, so it could explain not only the temporal variation of soil respiration, but also its spatial variation. Although this model might not be broadly applicable, the results suggested that there was significant spatial heterogeneity in soil respiration at the plant scale and root biomass dominated the small-scale spatial patterns of soil respiration. Thus, the models of soil respiration should not only take into account the influence of environmental factors, but also incorporate biotic factors in order to scale-up the chamber measurements of soil respiration to ecosystem level.

(C) 2006 Elsevier Ltd. All rights reserved.

Keywords: Soil respiration; Spatial variation; Biotic factors; Abiotic factors

\footnotetext{
*Corresponding author. Tel.: + 861062836268 ; fax: + 860182595962.

E-mail addresses: gxhan@ibcas.ac.cn (G. Han), gszhou@ibcas.ac.cn (G. Zhou).
}

\section{Introduction}

The soil is a major biospheric reservoir for carbon (C), containing globally twice as much $\mathrm{C}$ as the atmosphere and three times as much as vegetation (Granier et al., 2000). Soil respiration, which originates from autotrophic root 
respiration and heterotrophic microbial respiration in the rhizosphere and the bulk soil, provides the main carbon efflux from terrestrial ecosystems to the atmosphere and is therefore an important component of the global carbon balance (IPCC, 1996; Buchmann, 2000; Schlesinger and Andrews, 2000). Small changes in soil respiration across large areas can produce a great effect on $\mathrm{CO}_{2}$ atmospheric concentrations and provide a potential positive feedback between increasing temperature and enhanced soil respiration that may ultimately accelerate global warming (Grace and Rayment, 1999; Schlesinger and Andrews, 2000; Sánchez et al., 2003; Rodeghiero and Cescatti, 2005). Therefore, detailed information on soil respiration and its controlling factors is critical for constraining the ecosystem $\mathrm{C}$ budget and for understanding the response of soils to changing land use and global climate change (Lindroth et al., 1998; Buchmann, 2000; Tufekcioglu et al., 2001; Lee et al., 2004).

Soil respiration for a specific ecosystem can be characterized by its magnitude and its temporal and spatial variability (Fang et al., 1998). The rate of soil respiration is controlled primarily by the rate of $\mathrm{CO}_{2}$ production by biota within the soil, but is modified by factors influencing the $\mathrm{CO}_{2}$ movement out of the soil (Raich and Schlesinger, 1992; Tufekcioglu et al., 2001). Generally, soil temperature and soil moisture are considered the most influential environmental factors controlling soil respiration. These factors interact to affect the productivity of terrestrial ecosystems and the decomposition rate of soil organic matter, thereby driving the temporal variation of soil respiration (Wiseman and Seiler, 2004). Soil respiration also exhibits high levels of spatial heterogeneity, especially across small spatial scales in forest, grassland and farmland ecosystem at different time scales (Xu and Qi, 2001; Franklin and Mills, 2003; Maestre and Cortina, 2003). In order to accurately estimate $\mathrm{C}$ budgets in target ecosystems, we must be able to account for small-scale spatial variation in soil respiration (Maestre and Cortina, 2003; Adachi et al., 2005). Methods in quantifying spatial variation in soil respiration are limited and proved to be difficult (Rayment and Jarvis 2000; Tang and Baldocchi, 2005). The heterogeneity of vegetation coverage, root distribution, major environmental factors and soil properties contributes to the spatial variation of soil respiration (Xu and Qi, 2001; Maestre and Cortina, 2003; Epron et al., 2004; Tang and Baldocchi, 2005).

Researchers have developed data sets and processed models which are used to scale up chamber measurements of soil respiration to the ecosystem and larger scales (Raich and Schlesinger, 1992; Fang et al., 1998; Maestre and Cortina, 2003; Reth et al., 2004; Melling et al., 2005). These models typically use soil temperature (Fang et al., 1998; Buchmann, 2000; Janssens and Pilegaard, 2003), soil moisture (Davidson et al., 1998; Epron et al., 2004; Sotta et al., 2004) as well as their interaction (Tufekcioglu et al., 2001; Lee et al., 2002; Tang and Baldocchi, 2005) for largescale soil respiration estimates. However, whereas soil temperature and moisture are good predictors of the temporal variation of soil respiration, they are inadequate to explain the spatial variations of soil respiration within a site and between sites (Xu and Qi, 2001; Tang and Baldocchi, 2005). The spatial upscaling of soil respiration from field measurements to ecosystem levels will be biased without studying its spatial variation (Tang and Baldocchi, 2005). Therefore, it is necessary to incorporate both temporal and spatial variation of soil respiration into the model in order to scale-up the chamber measurements of soil respiration to ecosystem level (Xu and Qi, 2001).

Cropland amounts to about $12 \%$ of the earth's surface (Verma et al., 2005), and there is a general agreement that many agricultural ecosystems have the potential to sequester large amounts of $\mathrm{C}$ and support enhancing $\mathrm{C}$ sequestration in the soil (Freibauer et al., 2004; Smith, 2004). However, C dynamics has been less studied in agricultural ecosystems as compared with other ecosystems. In this study, we investigated the effects of environmental factors, root biomass and net Primary Productivity (NPP), soil characteristics and measurement positions on soil respiration in a maize (Zea mays L.) ecosystem during the growth season in 2005. Specifically, the objectives of this study were: (1) to characterize the spatial variation of soil respiration in a maize ecosystem, and to relate this spatial variation to environmental conditions; (2) to address the relative influence of soil temperature, soil moisture, fine root biomass, NPP and soil characteristics in explaining the variation of soil respiration at different temporal scales; and (3) to develop a model incorporating biotic factors as predictor variables to estimate reliably soil respiration and specifying the spatial and temporal variation of soil respiration in a maize ecosystem.

\section{Materials and methods}

\subsection{Study site}

The study was conducted in a spring maize ecosystem located on Jinzhou Agricultural Ecosystem Research Station $\left(41^{\circ} 09^{\prime} \mathrm{N}, 121^{\circ} 12^{\prime} \mathrm{E}\right)$, which belongs to Institute of Atmospheric Environment, China Meteorological Administration. The selected crop type was rainfed spring maize, which is the main crop type, and it was sown and harvested in early May and late September, respectively. The field was under till management and $\mathrm{N}$ fertilizer was around $300 \mathrm{~kg} \mathrm{Nha}^{-1}$.

The region has a temperate zone monsoon climate with a mean annual temperature of about $9.1{ }^{\circ} \mathrm{C}$ and an annual precipitation of about $568.8 \mathrm{~mm}$. The mean temperature during the growing season is $20.1{ }^{\circ} \mathrm{C}$. The study site is relatively flat with slopes $<3^{\circ}$ and the elevation is $17 \mathrm{~m}$. The soil type is typical brown soil, with a $\mathrm{pH}$ value of 6.3 , organic matter content from $0.6 \%$ to $0.9 \%$ and total $\mathrm{N} 0.069 \%$. The analysis data apply to $A_{\mathrm{p}}$ horizon at depths of $0-30 \mathrm{~cm}$. 


\subsection{Soil respiration measurements}

Soil respiration rates were measured monthly during the growing season (from May to September) in 2005 using a soil chamber (LI-6400-09, Li-Cor, Inc., Lincoln, NE) connected to a portable infrared gas analyzer (IRGA, LI-6400, Li-Cor, Inc., Lincoln, NE). To minimize soil surface disturbances, the chamber was mounted on PVC soil collars sharpened at the bottom. The soil collars were inserted into the soil to about 1 or $2 \mathrm{~cm}$ and installed one day before the measurements. The plants grew in rows with spacing of $60 \mathrm{~cm}$ and the plant distance within rows was $30 \mathrm{~cm}$. To assume that a radial gradient in root biomass persisted on space scale, there would be obvious difference in root biomass in these soil collars at different distances from the plant. Therefore, according to this hypothesis, 15 collars, each with a height of $4.5 \mathrm{~cm}$ and a diameter of $11 \mathrm{~cm}$, were placed at different distances from plants in order to investigate the spatial variation in soil respiration. According to the distance from the plants, the measurement positions could be divided into 3 groups: near a plant (1-5 cm from a plant), inter-plants $(8-15 \mathrm{~cm}$ from the plant) and inter-rows $(20-30 \mathrm{~cm}$ from the plant). Five collars were placed in each of the 3 positions for each of the 7 measurement periods. Soil respiration rates were measured every hour from 6:00 to 18:00 at clear days. A short sampling period, ranging from 1 to $3 \mathrm{~min}$ at each collar in accordance with the $\mathrm{CO}_{2}$ concentrations inside the chamber, was used in order to complete sampling from the whole 15 points as quickly as possible and to minimize soil temperature variation over the sampling period.

\subsection{Measurements of environmental factors}

Soil temperature was measured simultaneously with soil respiration using a copper/constantan thermocouple penetration probe (LI-6400-09 TC, LiCor) inserted in the soil to a depth of $10 \mathrm{~cm}$ in the vicinity of the soil collars. Soil water content $(0-12 \mathrm{~cm}$ and $0-20 \mathrm{~cm}$ depth, based on as soil volume) in the vicinity of the soil collars was monitored with a portable sensor (Diviner2000, Sentek, Australia). Both soil temperature and moisture were measured continuously in the same area as soil respiration measurements.

The plant aboveground biomass was measured by clipping 5 maize plants at intervals of $20 \mathrm{~d}$ from the beginning of May to the end of September. At the same time root biomass was measured by taking five soil blocks $(15 \mathrm{~cm}$ wide $\times 30 \mathrm{~cm}$ long $\times 30 \mathrm{~cm}$ deep $)$. Plant aboveground and root biomass were oven dried at $80^{\circ} \mathrm{C}$ for $48 \mathrm{~h}$ and weighed. The weight difference of total biomass between the two sampling periods was the NPP. In order to evaluate the effect of root biomass on soil respiration, soil samples up to $30 \mathrm{~cm}$ were excavated from each soil collar using a corer of $10 \mathrm{~cm}$ diameter after the soil respiration measurements. Each sample was washed by $0.2 \mathrm{~mm}$ mesh steel screen and live roots picked by hand. Sorted roots were weighed after drying at $80^{\circ} \mathrm{C}$ to a constant mass.

The soil samples of $30 \mathrm{~cm}$ depth in each soil collar were analyzed for soil water content (Oven-drying method), total C (Walkley-Black wet oxidation technique, Nelson and Sommers, 1982) and soil nitrogen (Kjeldahl method, Bremner, 1960).

\subsection{Statistical analysis}

Differences between measurement positions (near plants, inter-plants and inter-rows) in soil respiration were evaluated with one-way ANOVA. Linear regression was used to evaluate the relationships between soil respiration rates and dry root weights. Nonlinear regression analyses were used to describe the relationships between parameters in equations and environmental factors at different temporal scales. Significant differences for all statistical tests were evaluated at the level $\alpha=0.05$. All the statistical analyses were performed by using the SPSS 11.0 package (SPSS, Chicago, IL, USA).

\section{Results and discussion}

\subsection{Spatial variations of soil respiration}

The spatial variability of soil respiration rates among the 15 sampling points in the plot was relatively high, with a coefficient of variation of $43 \%$ on June $5,28 \%$ on June 28 , $55 \%$ on July $28,50 \%$ on August 28 and $53 \%$ on September 22. There was a significant spatial pattern for soil respiration of the maize ecosystem in 2005. Higher soil respiration rates tended to occur near the maize plant during the growing season (Fig. 1). Soil respiration emitted generally at the following sequence measurement positions: near the plants $>$ inter-plants $>$ inter-rows. Additionally,

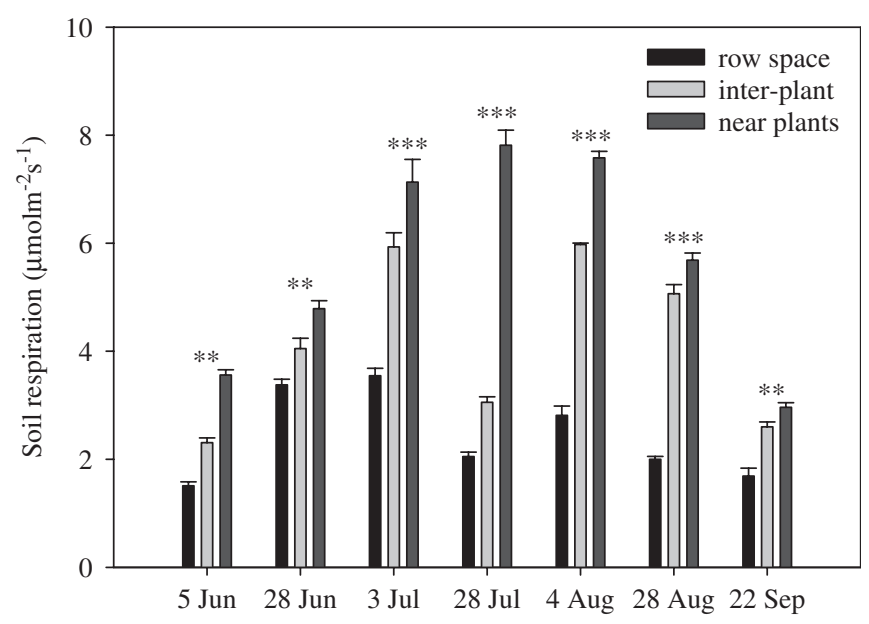

Fig. 1. Mean soil respiration rates of three measurement positions during maize growing season in 2005. Significant differences among measurement positions (after paired $t$-tests) are denoted by asterisks: ${ }^{* *} P<0.01$ and $* * * P<0.001$. Error bars represent $\pm 1 \mathrm{SE}(n=5)$. 
the temporal variation of soil respiration between rows collars was less pronounced than that within rows collars.

At present, the dynamic closed-chamber infrared gas analyzer system is used widely to measure soil respiration, such as LI-6400. Portable chamber measurements provide a useful tool to study spatial pattern of soil respiration (Tang and Baldocchi, 2005). In order to accurately estimate soil respiration, the spatial variations in biotic factors should been taken into account because of the unique spatial gradients of plant arrangement and root distribution in plantations and farmland ecosystems. However, the positions of chambers or soil collars were not described in detail (Lohila et al., 2003; Cao et al., 2004; Gough and Seiler, 2004; Wiseman and Seiler, 2004). In this study, we arranged 15 soil collars according to the distance from the plants in each measurement in order to describe statistically the spatial variability of soil respiration.

In previous research, the similar small-scale spatial patterns of soil respiration have been described in a series of ecosystems. For example, Fang et al. (1998) observed that $\mathrm{CO}_{2}$ effluxes from the soil under palmetto were significantly higher than that from the open floor. Pangle and Seiler (2002) observed significantly greater soil respiration rates near the base of pine seedlings in comparison to rates away from the seedlings. Wiseman and Seiler (2004) also reported mean soil respiration rates were consistently higher near the tree in plantation loblolly pine. And, higher values of soil respiration were also recorded in the vicinity of trunks than in the middle of the inter-rows (Epron et al., 2004).

It is apparent from our research and the researches cited above that there is likely significant spatial heterogeneity in soil respiration within a site and between sites at different space scales. Thus, in order to accurately estimate soil respiration, the arrangement of soil collars and the spatial variation in biotic factors and soil features should been taken into account, which remain a challenging yet critical area for future research (Maestre and Cortina, 2003).

\subsection{Effect of root biomass on soil respiration}

Microclimate and soil characteristics had no significant difference among plots across a single site at the same observation time and there were no significant correlations between soil respiration, soil temperature, soil moisture, soil $\mathrm{C}$ and total nitrogen $(\mathrm{N})$ content (Table 1). Correlation analysis revealed that fine root biomass in soil collars was significantly related to soil respiration rates across a single site at one measurement moment (Table 1), indicating soil respiration differed in plots with greater and less root biomass under the same environmental conditions, which were similar to previous reports (Maier and Kress, 2000; Pangle and Seiler, 2002; Wiseman and Seiler, 2004; Jia et al., 2005).

Fig. 2 shows soil respiration rates at different sampling locations plotted against root biomass in soil collars at 6:00 on 28 July. There was a significant linear relationship between soil respiration rate and root biomass $\left(R^{2}=0.73\right.$, $P<0.001)$ ignoring the data from point 12 where root biomass seemed to be abnormally high and the data from point 13 where soil respiration rate was abnormally high (Fig. 2). Similarly, we configured the linear relationship existing between soil respiration rate and root biomass from 7:00 to 18:00 on 28 July

$\mathrm{SR}=\alpha B+\beta$,

where $\mathrm{SR}$ is the soil respiration rate $\left(\mu \mathrm{mol} \mathrm{m}{ }^{-2} \mathrm{~s}^{-1}\right), B$ is root biomass in the soil collars $\left(\mathrm{gm}^{-2}\right), \alpha$ and $\beta$ are parameters and they were shown in Table 2.

On one measurement moment, soil respiration increased with increase in root biomass (Eq. $\left(1^{\prime}\right)$ ), while microclimate and soil characteristic had no significant differences among

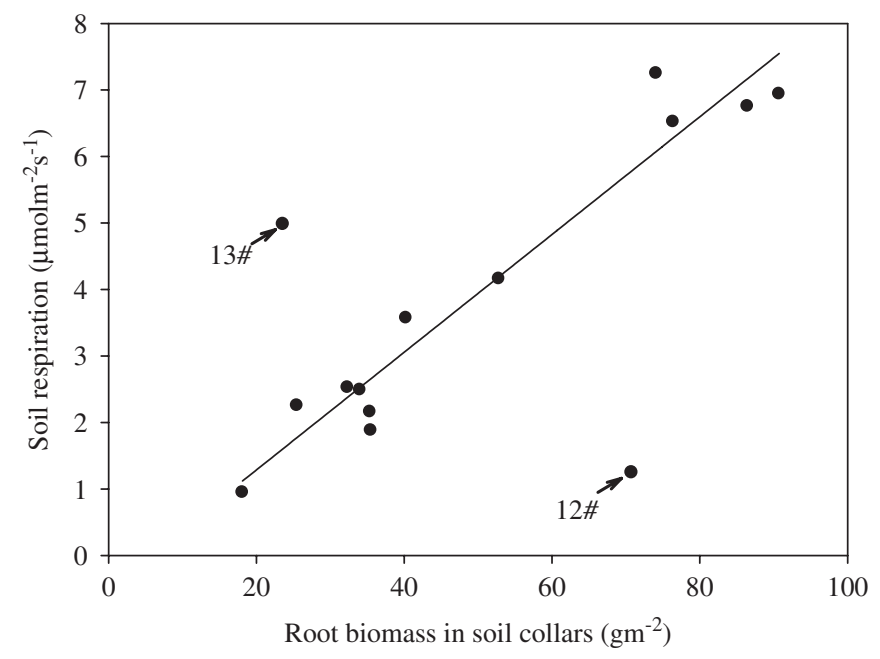

Fig. 2. Relationship between soil respiration rate and root biomass in soil collars at 6:00 on July 28 . The lines represent linear regression $\left(R^{2}=0.73\right.$, ignoring data of point 12,13$)$.

Table 1

The correlation coefficients of soil respiration rate to environmental factors among plots across a single site at the same observation time

\begin{tabular}{|c|c|c|c|c|c|c|}
\hline Date & $T_{\text {soil }}$ at $10 \mathrm{~cm}$ depth $\left({ }^{\circ} \mathrm{C}\right)$ & Soil moisture at $10 \mathrm{~cm}$ depth $(\%)$ & Root biomass $\left(\mathrm{gm}^{-2}\right)$ & Total C (\%) & Total N $(\%)$ & $\mathrm{C}: \mathrm{N}$ \\
\hline June 5 & -0.272 & 0.235 & $0.834^{* *}$ & -0.358 & -0.492 & 0.103 \\
\hline June 28 & 0.332 & -0.489 & $0.714^{* *}$ & 0.425 & 0.574 & 0.572 \\
\hline July 28 & 0.149 & -0.395 & $0.918^{* *}$ & 0.672 & -0.265 & 0.613 \\
\hline August 28 & 0.135 & 0.078 & $0.795^{* *}$ & 0.434 & 0.520 & -0.511 \\
\hline September 22 & -0.201 & -0.288 & $0.850 * *$ & -0.351 & -0.693 & -0.156 \\
\hline
\end{tabular}

${ }^{* *}$ Correlation is significant at the 0.01 level (2-tailed). 
Table 2

Regression equations between soil respiration rate and root biomass from 6:00 to $18: 00$ on July 28

\begin{tabular}{|c|c|c|c|c|c|}
\hline \multirow[t]{2}{*}{ Time } & \multicolumn{2}{|c|}{$\begin{array}{l}\text { Regression equation } \\
\mathrm{SR}=\alpha \beta+\beta\end{array}$} & \multirow[t]{2}{*}{$r^{2}$} & \multirow{2}{*}{$\begin{array}{l}\text { Soil } \\
\text { temperature at } \\
10 \mathrm{~cm} \text { depth } \\
\left({ }^{\circ} \mathrm{C}\right)\end{array}$} & \multirow{2}{*}{$\begin{array}{l}\text { Soil moisture } \\
\text { at } 10 \mathrm{~cm} \\
\text { depth }(\%)\end{array}$} \\
\hline & $\alpha$ & $\beta$ & & & \\
\hline $6: 00$ & 0.0885 & -0.4839 & 0.730 & 19.8 & 34.9 \\
\hline $7: 00$ & 0.0866 & -0.3298 & 0.706 & 19.0 & 34.9 \\
\hline $8: 00$ & 0.0909 & -0.2549 & 0.673 & 18.3 & 34.9 \\
\hline $9: 00$ & 0.1000 & -0.2324 & 0.692 & 19.3 & 34.8 \\
\hline 10:00 & 0.1025 & -0.3072 & 0.737 & 21.4 & 34.8 \\
\hline 11:00 & 0.0983 & -0.0728 & 0.689 & 23.7 & 34.9 \\
\hline $12: 00$ & 0.1160 & -0.4122 & 0.697 & 25.3 & 34.9 \\
\hline $13: 00$ & 0.1195 & -0.3742 & 0.705 & 26.5 & 35.1 \\
\hline $14: 00$ & 0.1268 & -0.7169 & 0.713 & 27.4 & 35.2 \\
\hline $15: 00$ & 0.1282 & -0.8339 & 0.730 & 27.9 & 35.2 \\
\hline $16: 00$ & 0.1281 & -0.8156 & 0.742 & 27.3 & 35.2 \\
\hline 17:00 & 0.1322 & -1.0059 & 0.730 & 27.6 & 35.2 \\
\hline 18:00 & 0.1294 & -0.8742 & 0.734 & 27.0 & 35.2 \\
\hline
\end{tabular}

measurement points across a single site, indicating root biomass exerted significant influence on the spatial pattern of soil respiration under the same environmental conditions. The result was consistent with previous reports about spatial variation of soil respiration for terrestrial systems (Maier and Kress, 2000; Stoyan et al., 2000; Pangle and Seiler, 2002; Wiseman and Seiler, 2004). Generally, a radial gradient in total root biomass likely persisted through a typical timber management rotation (Wiseman and Seiler, 2004). Within this radial gradient, greater root biomass existed near the plant than away from the plant, and root respiration decreased with increasing distance from a plant.

\subsection{Effects of root biomass in soil collars and soil temperature on soil respiration}

From Table 2, it was clear that coefficient $\alpha$ and $\beta$ in Eq. ( $\left.1^{\prime}\right)$ fluctuated at daily scale. Correlation analysis indicated that the daily changes in soil temperature at $10 \mathrm{~cm}$ depth explained differences in coefficient $\alpha$ and $\beta$ of the linear equation. Soil temperature markedly influenced the effect of root biomass on soil respiration by reducing the intercept $(\beta)$ of the linear equation and increasing significantly its slope $(\alpha)$

$\alpha=0.0423 e^{0.04 T} ; R^{2}=0.905, p<0.001$,

$\beta=-0.0572 T+0.8488 ; R^{2}=0.533, p=0.005$.

Substituting Eqs. $\left(2^{\prime}\right)$ and $\left(3^{\prime}\right)$ into $\left(1^{\prime}\right)$, an equation for estimating soil respiration at daily scale can be developed as

$\mathrm{SR}=a e^{b T} B+c T+d$.

By the same analysis, we found that soil respiration on June 5, June 28, August 28 and September 22 could be fitted using Eq. (4) and parameters $a, b, c$ and $d$ were shown
Table 3

Values of coefficients $a, b, c$ and $d$ of the equation $\mathrm{SR}=a e^{b T} B+c T+d$ between soil respiration rate and root biomass and soil temperature on June 4, June 28, July 28, August 28 and September 22, 2005

\begin{tabular}{llcccc}
\hline Date & \multicolumn{2}{l}{ Regression equation SR $=a e^{b T} B+c T+d$} & \multirow{2}{*}{$r^{2}$} \\
\cline { 2 - 4 } & $a$ & $b$ & $c$ & $d$ & \\
\hline June 5 & 0.1022 & 0.0381 & 0.0807 & -0.3459 & 0.94 \\
June 28 & 0.0341 & 0.0540 & -0.0379 & 1.8813 & 0.84 \\
July 28 & 0.0422 & 0.0401 & -0.0563 & 0.829 & 0.93 \\
August 28 & 0.0214 & 0.0387 & -0.0170 & 1.0225 & 0.85 \\
September 22 & 0.0389 & 0.0069 & 0.0165 & 0.4292 & 0.74 \\
\hline
\end{tabular}

in Table 3. Eq. (4) clearly demonstrated that soil respiration responded positively to changes in root biomass in soil collars. Furthermore, these responses would be impacted by soil temperature at daily scale. In other words, soil temperature ameliorated the positive relationship between soil respiration and root biomass in soil collars.

\subsection{Effects of root biomass, soil temperature, soil moisture and NPP on soil respiration at seasonal scale}

In order to develop a model of soil respiration at seasonal scale, the environmental factors that affected the parameter $a, b, c$ and $d$ in Eq. (4) must be determined during the growing season. Regression analysis was used to examine the influence of environmental factors (soil temperature, soil moisture, shoot biomass, root biomass, total biomass, NPP, soil total $\mathrm{C}$ and total $\mathrm{N}$ content) on the parameter $a, b, c$ and $d$ in Eq. (4). We found that soil moisture was the best predictor of parameter $a$, and that soil temperature was the best predictor of parameter $b$ and NPP was the driving factors of parameter $c$. However, there were no environmental factors that significantly affected parameter $d$

$a=-1.7063 W+0.6392 ; R^{2}=0.702$,

$b=0.0009 e^{0.1599 T} ; R^{2}=0.975$,

$c=-0.0034 \mathrm{NPP}+0.0639 ; R^{2}=0.864$.

Substituting Eqs. (5) and (7) into (4) and ignoring Eq. (6) because parameter $b$ was inherently the coefficient of soil temperature, a simplified equation for estimating soil respiration can be developed as

$\mathrm{SR}=(a W+b) e^{c T} B+(d \mathrm{NPP}+e) T+f$,

where $W$ was soil moisture (\%), $a, b, c, d, e$ and $f$ are parameters to be determined.

Fitting the field data to Eq. (8) reached a good agreement between observed and predicted soil respiration rates from different sampling points and different temporal scales (Fig. 3), the squared correlation coefficient was $78 \%$ $(n=518)$. Most of the temporal and spatial variability in soil respiration could be explained by the variations in soil 


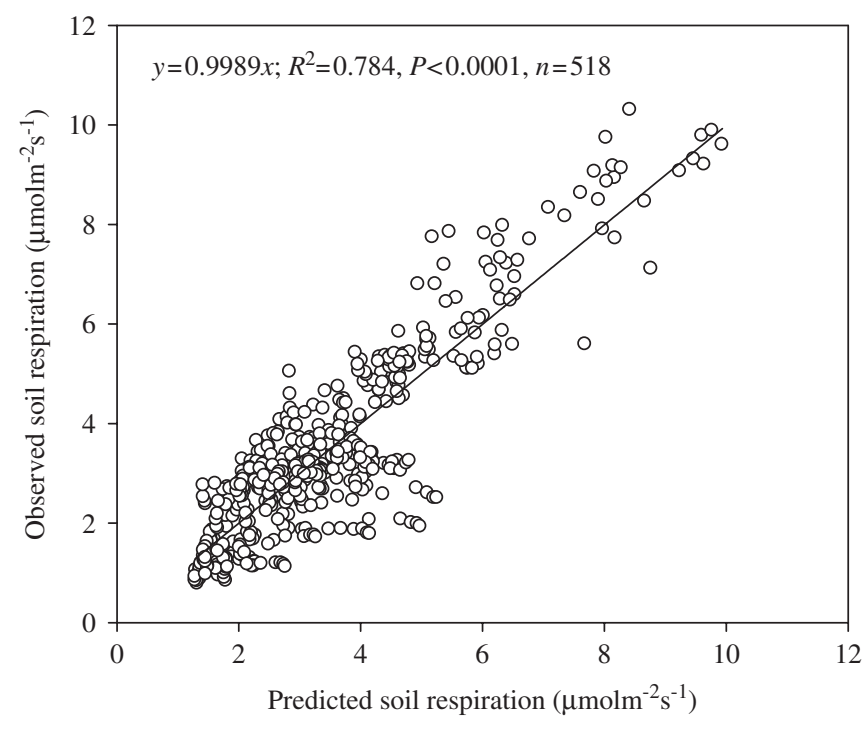

Fig. 3. Predicted soil respiration rates plotted against observed values.

temperature, soil moisture and associated live root biomass and NPP defined in Eq. (8).

According to Eq. (8), we could simulate instantaneous soil respiration rates, which could explain not only the temporal variation of soil respiration, but also the spatial variation of soil respiration. Eq. (8) not only took into account the influence of soil temperature and moisture, but also incorporated biotic factors as predictor variables, which would lead to an improvement in predictive capabilities of the model. The biotic factors have also been shown to have an effect on soil respiration; on the one hand, respiring roots directly below the measurement chamber exerts significant influence on soil respiration since root respiration is an integral part of soil respiration (Hanson et al., 2000), on the other hand, root exudates from assimilating production and root litter allocated into the soil during the growing season enhance the soil respiration by stimulating microbial growth and activity (Lohila et al., 2003). Therefore, it is dangerous to predict soil respiration just according to soil temperature and moisture when changes in root biomass can confound the temperature dependence of soil respiration (Janssens and Pilegaard, 2003). In addition, NPP was another factor influencing soil respiration during the growing season of maize. NPP may be the most important factor controlling soil biota and belowground processes at the ecosystem scale (Wardle, 2002). There was strong evidence that rates of plant production and soil respiration were linked processes (Raich and Tufekcioglu, 2000). Root respiration was likely to be sensitive to seasonal changes in NPP, because root respiration largely depended on the amount of photosynthates translocated from the aboveground part of the plant (Högberg et al., 2002; Curiel-Yuste et al., 2004). Moreover, NPP could provide the inputs to the soil of aboveground litter and belowground organic detritus (Raich and Potter, 1995). Thus, the incorporation of biotic factors (root biomass, NPP) into Eq. (8) might have more biological functions for evaluating the spatial and temporal variation of soil respiration on agricultural sites.

Soil total $\mathrm{C}$ and total $\mathrm{N}$ content were not significantly correlated with soil respiration at the plant scale during growing season. Mineral soil carbon represented potential carbon substrate sources for microbes and could accordingly affect microbial activity (Wang et al., 2002). Gough and Seiler (2004) reported that mineral soil carbon explained a small amount of variance of soil respiration in loblolly pine plantations. However, in this study soil properties in collars may not be good indicators of soil respiration for two reasons. First, soil properties may be more homogeneous as the impact of tillage practice in maize ecosystem. Second, soil total $\mathrm{C}$ and total $\mathrm{N}$ did not fluctuate remarkably during growing season. Russell and Voroney (1998) reported that less than $2 \%$ of the observed variance in soil respiration in a boreal aspen forest was explained by soil organic matter quantity sampled directly below measurement chambers.

\subsection{Features and limitations of the model}

Eq. (8) could simulate instantaneous soil respiration rates from different sampling points and different temporal scales, so it could not only explain the temporal variation of soil respiration, but also explain the spatial variation of soil respiration. Temporal patterns of soil respiration have been simulated by the continuous records of temperature, moisture and other variables (Fang et al., 1998; Buchmann, 2000; Janssens and Pilegaard, 2003). However, the spatial difference of soil respiration within a site and between sites is often not explained by climatic variables (Tang and Baldocchi, 2005). By taking advantage of the unique spatial gradients of root distribution in maize ecosystem to study the spatial variation in soil respiration, this study determined that root biomass in soil collars exerted significant influence on the spatial pattern of soil respiration. Thus, biotic factors were incorporated into the model as predictor variables, so it could explain the spatial and temporal variation of soil respiration within a site during growing season.

The model may be suitable for farmland ecosystems and uniform plantations and may not be broadly applicable in natural ecosystems. In this study, it was assumed that root biomass dominated the distribution of soil respiration, and this relationship was expressed by Eq. $\left(1^{\prime}\right)$. The terrain was relatively flat and soil properties were more homogeneous as the impact of tillage practice in maize ecosystem. Otherwise, the other vegetation was less under maize plants. Thus, root biomass exerted significant influence on the spatial variation of soil respiration assumed the influence of vegetation communities, soil properties and moisture content on the spatial variability of soil respiration was negligible. Fig. 3 indicated that these assumptions were adequate. However, these conditions may not be met in some natural ecosystems because of the spatial variation 
of vegetation under storey plants and surface soil features. Stoyan et al. (2000) ascribed soil respiration concentrated around the trunk to higher soil water content as a result of stem flow in poplars plantation. Pangle and Seiler (2002) found the spatial pattern of soil $\mathrm{CO}_{2}$ efflux between plots was most influenced by differences in soil nitrogen and pine root biomass in a loblolly pine stand on a single day. Maestre and Cortina (2003) highlighted the spatial variation of both vegetation and surface soil features affecting soil respiration rates in semiarid ecosystems.

\section{Conclusions}

Our results give clear indications that there is significant spatial heterogeneity in soil respiration at the plant scale and root biomass dominates the small-scale spatial pattern of soil respiration. This phenomenon also suggests that the spatial variation in biotic factors and soil features should been taken into account in order to accurately estimate soil respiration. We suggest that interactions among soil temperature, soil moisture, root biomass and NPP largely control the temporal and spatial variation in soil respiration during the growing season. This strongly suggests that the models of soil respiration should not only take into account the influence of environmental factors, but also incorporate biotic factors in order to scale-up the chamber measurements of soil respiration to ecosystem level, which could undoubtedly lead to an improvement in predictive capabilities of the model.

\section{Acknowledgements}

We thank Dr. Ensheng Weng, Dr. Yuhui Wang, Dr. Yanling Jiang, Ms. Jian Song, Dr. Bingrui Jia, Dr. Li zhou, Dr. Fengyu Wang, Dr. Xu Wang, Dr. Yijun Li and Dr. Yunlong Wang for their help during the experiments. Dr. Xuhui Zhou of the University of Oklahoma also provided many helpful suggestions. This work was jointly supported by the National Key Project for Basic Research (2006CB400502) and the Knowledge Innovation Programs of the Chinese Academy of Sciences (KSCX2-SW-133).

\section{References}

Adachi, M., Bekku, Y.S., Konuma, A., Kadir, W.R., Okuda, T., Koizumi, H., 2005. Required sample size for estimating soil respiration rates in large areas of two tropical forests and of two types of plantation in Malaysia. Forest Ecology and Management 210, 455-459.

Bremner, J.M., 1960. Determination of nitrogen in soil by the Kjeldahl method. Journal of Agricultural Science 55, 11-33.

Buchmann, N., 2000. Biotic and abiotic factors controlling soil respiration rates in Picea abies stands. Soil Biology \& Biochemistry 32, 1625-1635.

Cao, G.M., Tang, Y.H., Mo, W.H., Wang, Y.S., Li, Y.N., Zhao, X.Q., 2004. Grazing intensity alters soil respiration in an alpine meadow on the Tibetan plateau. Soil Biology \& Biochemistry 36, 237-243.

Curiel-Yuste, J., Janssens, I.A., Carrara, A., Ceulemans, R., 2004. Annual $\mathrm{Q}_{10}$ of soil respiration reflects plant phonological patterns as well as temperature sensitivity. Global Change Biology 10, 161-169.
Davidson, E.A., Belk, E., Boone, R.D., 1998. Soil water content and temperature as independent or confounded factors controlling soil respiration in a temperate mixed hardwood forest. Global Change Biology 4, 217-227.

Epron, D., Nouvellon, Y., Roupsard, O., Mouvondy, W., Mabialab, A., Laurent, S.A., Joffre, R., Jourdan, C., Bonnefond, J.M., Berbigier, P., Hamel, O., 2004. Spatial and temporal variations of soil respiration in a Eucalyptus plantation in Congo. Forest Ecology and Management 202, 149-160.

Fang, C., Moncrieff, J.B., Gholz, H.L., Clark, K.L., 1998. Soil CO $\mathrm{CO}_{2}$ efflux and its spatial variation in a Florida slash pine plantation. Plant and Soil 205, 135-146.

Franklin, R.B., Mills, A.L., 2003. Multi-scale variation in spatial heterogeneity for microbial community structure in an eastern Virginia agricultural field. FEMS Microbiology Ecology 44, 335-346.

Freibauer, A., Rounsevell, M.D.A., Smith, P., Verhagen, J., 2004. Carbon sequestration in the agricultural soils of Europe. Geoderma 122 (1), $1-23$.

Grace, J., Rayment, M., 1999. Respiration in the balance. Nature 404, 819-820.

Granier, A., Ceschia, E., Damesin, C., Dufrene, E., Epron, D., Gross, P., Lebaube, S., Le Dantec, V., Le Goff, N., Lemoine, D., 2000. The carbon balance of a young Beech forest. Functional Ecology 14, 312-325.

Gough, M., Seiler, J.R., 2004. The influence of environmental, soil carbon, root, and stand characteristics on soil $\mathrm{CO}_{2}$ efflux in loblolly pine (Pinus taeda L.) plantations located on the South Carolina Coastal Plain Christopher. Forest Ecology and Management 191, 353-363.

Hanson, P.J., Edwards, N.T., Garten, C.T., Andrews, J.A., 2000. Separating root and soil microbial contributions to soil respiration: a review of methods and observations. Biogeochemistry 48, 115-146.

Högberg, P., Nordgren, A., Ågren, G.I., 2002. Carbon allocation between tree root growth and root respiration in boreal pine forest. Oecologia 132, 579-581.

IPCC, 1996. Climate Change 1995. The Science of Climate Change. Cambridge University Press, Cambridge, 572pp.

Janssens, I.A., Pilegaard, K., 2003. Large seasonal changes in $Q_{10}$ of soil respiration in a beech forest. Global Change Biology 9, 911-918.

Jia, B.R., Zhou, G.S., Wang, F.Y., Wang, Y.H., Yuan, W.P., Zhou, L., 2005. Partitioning root and microbial contributions to soil respiration in Leymus chinensis populations. Soil Biology \& Biochemistry 38, 653-660.

Lee, M.S., Nakane, K., Nakatsubo, T., Mo, W.h., Koizumi, H., 2002. Effects of rainfall events on soil $\mathrm{CO}_{2}$ flux in a cool temperate deciduous broad-leaved forest. Ecological Research 17, 401-409.

Lee, X.H., Wu, H.J., Sigler, J., Oishi, C., Siccama, T., 2004. Rapid and transient response of soil respiration to rain. Global Change Biology 10, 1017-1026.

Lindroth, A., Grelle, A., Moren, A., 1998. Long-term measurements of boreal forest carbon balance reveal large temperature sensitivity. Global Change Biology 4, 443-450.

Lohila, A., Aurela, M., Regina, K., Laurila, T., 2003. Soil and total ecosystem respiration in agricultural fields: effect of soil and crop type. Plant and Soil 251, 303-317.

Maestre, F.T., Cortina, J., 2003. Small-scale spatial variation in soil $\mathrm{CO}_{2}$ efflux in a Mediterranean semiarid steppe. Applied Soil Ecology 23, 199-209.

Maier, C.A., Kress, L.W., 2000. Soil $\mathrm{CO}_{2}$ evolution and root respiration in 11-year-old loblolly pine (Pinus taeda) plantations as affected by moisture and nutrient availability. Canada Journal of Forest Research 30, 347-359.

Melling, L., Hatano, R., Goh, K.J., 2005. Soil $\mathrm{CO}_{2}$ flux from three ecosystem in tropical peatland of Sarawak, Malaysia. Tellus 57B, 1-11.

Nelson, D.W., Sommers, L.E., 1982. Total carbon, organic carbon and organic matter. In: Page, A.L., Miller, R.H., Keeney, D.R. (Eds.), Methods of Soil Analysis. American Society of Agronomy, Madison, WI, USA, pp. 539-579. 
Pangle, R.E., Seiler, J.R., 2002. Influence of seedling roots, environmental factors and soil characteristics on soil $\mathrm{CO}_{2}$ efflux rates in a 2-year-old loblolly pine (Pinus taeda L.) plantation on the Virginia Piedmont. Environmental Pollution 116, B85-B96.

Raich, J.W., Potter, C.S., 1995. Global patterns of carbon-dioxide emissions from soils. Global Biogeochemistry Cycle 9, 23-36.

Raich, J.W., Schlesinger, W.H., 1992. The global carbon dioxide flux in soil respiration and its relationship to vegetation and climate. Tellus 44B, 81-99.

Raich, J.W., Tufekcioglu, A., 2000. Vegetation and soil respiration: correlations and controls. Biogeochemistry 48, 71-90.

Rayment, M.B., Jarvis, P.G., 2000. Temporal and spatial variation of soil $\mathrm{CO}_{2}$ efflux in a Canadian boreal forest. Soil Biology \& Biochemistry 32, 35-45.

Reth, S., Göckede, M., Falge, E., 2004. $\mathrm{CO}_{2}$ efflux from agricultural soils in Eastern Germany - comparison of a closed chamber system with eddy covariance measurements. Theoretical and Applied Climatology 85, 175-186.

Rodeghiero, M., Cescatti, A., 2005. Main determinants of forest soil respiration along an elevation/temperature gradient in the Italian Alps. Global Change Biology 11, 1024-1041.

Russell, C.A., Voroney, R.P., 1998. Carbon dioxide efflux from the floor of a boreal aspen forest. I. Relationship to environmental variables and estimates of C respired. Canadian Journal of Soil Science 78, 301-310.

Sánchez, M.L., Ozores, M.I., López, M.J., Colle, R., De Torre, B., García, M.A., Pérez, I., 2003. Soil $\mathrm{CO}_{2}$ fluxes beneath barley on the central Spanish plateau. Agricultural and Forest Meteorology 118, 85-95.

Schlesinger, W.H., Andrews, J.A., 2000. Soil respiration and the global carbon cycle. Biogeochemistry 48, 7-20.

Smith, P., 2004. Carbon sequestration in croplands: the potential in Europe and the global context. European Journal of Agronomy 20 (3), 229-236.
Sotta, E.D., Meir, P., Malhi, Y., Donatonobre, A., Hodnett, M., Grace, J., 2004. Soil $\mathrm{CO}_{2}$ efflux in a tropical forest in the central Amazon. Global Change Biology 10, 601-617.

Stoyan, H., De-Polli, H., Böhm, S., Robertson, G.P., Paul, E.A., 2000. Spatial heterogeneity of soil respiration and related properties at the plant scale. Plant and Soil 222, 203-214.

Tang, J.W., Baldocchi, D.D., 2005. Spatial-temporal variation in soil respiration in an oak-grass savanna ecosystem in California and its partitioning into autotrophic and heterotrophic components. Biogeochemistry $73,183-207$.

Tufekcioglu, A., Raich, J.W., Isenhart, T.M., Schultz, R.C., 2001. Soil respiration within riparian buffers and adjacent crop fields. Plant and Soil 229, 117-124.

Verma, S.B., Dobermann, A., Cassman, K.G., Walters, D.T., Knops, J.M., Arkebauer, T.J., Suyker, A.E., Burba, G.G., Amos, B., Yang, H.S., Ginting, D., Hubbard, K.G., Gitelson, A.A., Walter-Shea, E.A., 2005. Annual carbon dioxide exchange in irrigated and rainfed maizebased agroecosystems. Agricultural and Forest Meteorology 131, $77-96$.

Wang, C., Bond-Lamberty, B., Gower, S.T., 2002. Environmental controls on carbon dioxide flux from black spruce coarse woody debris. Oecologia 132, 374-381.

Wardle, D.A., 2002. Communities and Ecosystems, Linking the Aboveground and Belowground Components. Princeton University Press, Princeton, NJ, p. 392.

Wiseman, P.E., Seiler, J.R., 2004. Soil $\mathrm{CO}_{2}$ efflux across four age classes of plantation loblolly pine (Pinus taeda L.) on the Virginia Piedmont. Forest Ecology and Management 192, 297-311.

$\mathrm{Xu}, \mathrm{M}$., Qi, Y., 2001. Soil-surface $\mathrm{CO}_{2}$ efflux and its spatial and temporal variations in a young ponderosa pine plantation in northern California. Global Change Biology 7, 667-677. 